\title{
Research on Improvisation in the Course of Piano and Nursery Rhyme Playing and Singing in Preschool Education Major
}

\author{
Li Wang \\ Shandong Technician College of Water Conservancy, Zibo 255000, Shandong, China \\ Email: 40817843@qq.com
}

\begin{abstract}
Nowadays, the training goals of the preschool education major are constantly expanding with the society's deep understanding of early childhood education, and the requirements for students' various skills and professionalism have been improved. Among them, piano improvisation is the teaching content of the course of piano and nursery rhyme playing and singing in this major, and it is also an ability of great practical significance. Therefore, teachers should actively explore the value of piano improvisation ability, reflect on the problems in the current teaching situation, and find ways to optimize the teaching effect, which are very helpful to future teaching practice.
\end{abstract}

Keywords: preschool education, children's songs and singing, improvisation, methods

\section{Introduction}

In people's common perception, kindergarten teachers are "older children" who lead children to sing and dance. It seems that as long as you can sing nursery rhymes and do children's exercises, you can be a kindergarten teacher. In fact, as people pay more and more attention to early childhood education, the training of kindergarten teachers is becoming more and more professional, and the requirements for talent skills are getting higher and higher. Many kindergartens require kindergarten teachers to understand music theory, be able to play the piano, and even involve improvisation in various practical teaching activities. If kindergarten teachers do not possess this skill, they will have certain disadvantages in the preschool education workplace. Therefore, in terms of talent training, the preschool education major should teach students improvisation and help them accumulate improvisation experience.

\section{The value of piano improvisation}

The so-called improvisation refers to the process of allowing students to randomly compose and arrange music according to the environment they are in on the premise of mastering the theory of music. Obviously, improvisation tests students' ability to master music theory, and it also reflects whether students' piano playing experience is rich or not. Regarding the value of piano improvisation ability, the author enumerates the following aspects.

\subsection{As the key content of student education and training}

Piano improvisation has a high status in preschool education professional courses and is the key learning content for students. On the one hand, the ability to improvise is a must-have for every preschool education student ${ }^{[1]}$, and it also has a place in the academic assessment. On the other hand, preschool education students often face the evaluation requirements of improvisation when they enter the society to participate in the recruitment of kindergarten teachers ${ }^{[2]}$. It can be said that people have regarded improvisation as an important indicator of whether a graduate meets the evaluation standards of kindergarten teachers. As a key content, piano improvisation can not only integrate music theory, but also strengthen practice, which is a manifestation of students' comprehensive quality. And improvisation can also greatly stimulate the children's senses in the practice of children's teaching, allowing them to more truly feel the joyful atmosphere driven by the kindergarten teacher's playing and integrate them into the teaching situation.

\subsection{As a basis for judging students' ability}

A student who has come out of the preschool education major can perform improvisation, which shows that his professional ability is qualified, otherwise it is lacking. To achieve improvisation, students need to organically combine piano keyboard skills, music theory into practice, playing proficiency, and song type grasp, and finally synthesize a song through an individual's comprehensive understanding and creative expression of music Impromptu tracks. Therefore, improvisation in a sense represents the comprehensive music literacy of preschool education students ${ }^{[3]}$. 


\subsection{As a necessary means of future teaching}

Students learn to improvise, and ultimately they have to put it into their future preschool education practice. The final beneficiaries are the student himself and the young children he teaches. Nowadays, kindergartens have strengthened the awareness of children's comprehensive ability training, and they have paid great attention to the influence of music on children. And all the activities in the kindergarten may use music as a means of setting off the atmosphere. So as future kindergarten teachers, preschool education students can freely perform piano improvisation, which will help them engage in preschool education.

\section{The current situation of piano improvisation teaching}

\subsection{Students lack basic skills}

Although there are music classes in our compulsory education, music classes have always existed in a role similar to hobby classes, not exam subjects. Therefore, many students majoring in preschool education have very little knowledge of music theory, and some have zero foundation. These students are already struggling to learn music theory, and even become tired because they can't find points of interest, so they are even more incapable of improvisation when facing higher requirements in terms of comprehensive ability. Therefore, because students lack the basic skills related to music, teachers' improvisational guidance to them is hindered.

\subsection{Failure to achieve correct perception}

Piano improvisation requires students to have innovative consciousness and creative ability ${ }^{[4]}$, and it also helps to promote children's songs through the old and new, and new singing of old songs. However, in specific teaching guidance, teachers tend to focus on the practice of playing skills that can be directly reflected and visible, and lack of encouragement and attention to students' improvisation. In addition, students also experienced cognitive deviations when practicing playing. They believed that practicing more different styles of repertoire was the cultivation of improvisation, but did not focus on the actual needs of early childhood education. In this way, although students practice changing styles of playing, they may not be able to improvise a song that children love.

\subsection{Teaching methods have been lagging behind}

Contemporary families have increased their investment in the training of young children, and they have high expectations for the professional level of preschool teachers ${ }^{[5]}$. However, the teaching content and even methods of many preschool education majors have not kept up with the requirements of educational development, and there has been a dislocation of supply and demand. For the teaching of improvisation, music teachers generally pay more attention to guiding students' understanding and application of music theory and the playing skills required by the teaching materials, but are weak in improvisation content. Because some teachers themselves lack the experience of improvisation, there are not many good methods to provide ${ }^{[6]}$. In addition, teachers' teaching practice has no connection with the current preschool education situation. They often use textbooks as the general outline, with less expansion and less practice, which makes teaching and social needs out of touch. Sometimes improvisations that are too professional are beyond the scope of students' acceptance, making them feel that it is too difficult to deal with.

\section{Optimize the teaching methods of piano improvisation}

\subsection{Choose materials flexibly according to students' specific situation}

The selection of materials according to the specific situation of the students can include two aspects. On the one hand, the selection of materials is based on the specific conditions of preschool education students. Students majoring in preschool education often pass cultural courses, and are slightly poorer on the basis of music knowledge, and each of them has a different understanding of music and learning efficiency of piano instrument playing. Then, teachers should select the case materials for teaching, and don't blindly stare at those repertoires with strong skills and complicated musical melody. On the contrary, teachers should select, practice and guide students in a gradual manner based on the foundation of students. In the specific instruction process, teachers should also pay attention to inspiring students to realize the creative inspiration of musical works, so as to encourage them to actively work towards the direction of improvisation. At the same time, in terms of material types, teachers should also choose more artistically expressive and innovative tracks. On the other hand, materials are selected according to the actual needs of early childhood education. The preschool education major is intended to contribute talents to preschool education. Then its training direction and practice cannot be divorced from the reality of preschool education, and the front-line preschool education situation should be used as a reference from 
time to time to correct and improve teaching strategies. Therefore, when teachers lead students to practice improvisational performances, they must choose more children's songs that are simple but full of childishness and positiveness, and divide the attention of difficult songs into more practical materials.

\subsection{Seize the opportunity and activate the training methods}

Contemporary education attaches great importance to letting students play the main role in the classroom, while teachers transform into guiding roles. In the teaching of impromptu playing, teachers should also make such a transformation, discarding the former lecture-style music theory narration and solidified creation skills demonstration, and adopting a way that better reflects the students' individualized potential for teaching guidance. On the one hand, teachers can provide students with the opportunity to create independently after teaching certain music theory knowledge, such as letting them choose their favorite theme for an impromptu playing competition. In view of the fact that the students may not have a solid foundation and have little experience, teachers can not make too many demands on the difficulty, as long as they can create innovative and complete repertoires, they are encouraged. Teachers can also improve students' improvisation skills through daily playing training, such as arranging students to try a certain theme for playing practice before teaching a new class. After teaching the new knowledge, the teacher gives the students another opportunity to reimprove the practice content before the class, so that the two performances are in contrast, and then help the students to see their deficiencies and progress.

\subsection{Find a platform and strengthen practice}

In terms of the difficulty level of piano performance, the requirements for preschool education students are not too high, but it must be able to meet the needs of preschool education. This requires students to learn as much as possible about the real preschool education teaching situation and to have a stronger ability to organize actual teaching. Therefore, teachers should organize more students to carry out impromptu performance competitions on campus, or allow students to participate more in cultural and recreational activities held on campus to accumulate practical experience. Teachers can also look for more opportunities for students to participate in the teaching of surrounding kindergartens, such as acting as kindergarten volunteers, bringing joy to the children, and taking advantage of some opportunities to show piano playing and improvisational ability.

\subsection{Explore independently and encourage creation}

If the piano playing level and technique belong to the player's hard power, then his artistic imagination and emotional sensitivity are soft power. In order to improvise and perform outstanding works, students need to have rich association skills and express the emotions they feel with the help of melody. Therefore, in daily teaching, teachers should consciously lead students to make associations with music situations, so as to promote the development of their sensibility, and ultimately help independent creation. For example, teachers can instruct students to associate various piano sounds with the environment and scenes in their memory, and encourage students to improvise based on the atmospheric characteristics of the environment and the situation.

\section{Conclusion}

The level of students' piano improvisation is personally related to their future employment and career development. In terms of their occupation, it is related to the musical enlightenment and emotional enlightenment of every child they teach. Therefore, piano teachers of preschool education must face improvisation teaching with a double sense of responsibility. They must select students' training materials and repertoires, renew their guidance methods, and encourage students' practice and improvisation. It is also necessary to look at teaching from a developmental perspective, and constantly improve personal coaching level in teaching reflection.

\section{References}

[1] Bai Jie. On the practical teaching of nursery rhymes and singing lessons for preschool education majors. SHENHUA (Part Three). 2019; (5): 136-136.

[2] Su Yi. On the cultivation of playing and singing ability of students majoring in preschool education in higher vocational education. Northern Music. 2019; 39(17): 156+159.

[3] Hu Jingjing. The application of piano impromptu accompaniment in preschool education majors in teaching practice. Music Education and Creation. 2019; 000(012): 19-23. 
[4] Wang Dan. Piano teaching in higher vocational preschool education based on nursery rhyme accompaniment training. Northern Music. 2019; 39(06): 130-131.

[5] Chen Yu. On the cultivation of children's songs and singing ability of students majoring in pre-school education in higher vocational colleges. The Farmers Consultant. 2020; 657(11): 252-252.

[6] Wei Yuan. A Preliminary Study of Children's Songs and Singing Courses for Preschool Education Majors in Higher Vocational Education. Youth Years. 2019; 000(007): 151. 